\title{
Multilayer composite nanoscale coatings as a method to increase reliability and tool life of cutting tools made of mixed ceramic $\mathrm{Al}_{2} \mathrm{O}_{3}-\mathrm{TiC}$
}

\author{
Sergey N. Grigoriev ${ }^{1, a}$ and Alexey A. Krapostin ${ }^{2}$ \\ 1 Moscow State University of Technology "STANKIN", Vadkovsky per. 1, Moscow 127994, Russia \\ 2 JSC "Plant named after G.K. Korolev", st. Zvereva-22, Ivanovo 153003, Russia
}

Received 18 October 2016, Accepted 29 November 2016

\begin{abstract}
The paper studies the challenges of improvement of reliability and tool life of ceramic cutting tools made of mixed ceramic $\mathrm{Al}_{2} \mathrm{O}_{3}$-TiC through application of nanoscale multilayer composite coatings, deposited through the method of filtered vacuum arc deposition. The paper studied wear mechanisms of ceramic cutting tools with and without coatings, as well as reliability of ceramic tools. It is found out that coatings reduce the wear rate of a ceramic tool along its flank face. The difference between flank wear land $V B$ for an uncoated ceramic tool and a ceramic tool with coating reaches up to $60 \mu \mathrm{m}$ during cutting time of 10-12 min, with the better results on reduction of the wear rate of flank wear land shown by ceramic cutting inserts with nanoscale multilayer coating $\mathrm{Ti}-(\mathrm{TiAl}) \mathrm{N}-(\mathrm{TiCrAl}) \mathrm{N}$ as compared with coating $\mathrm{Ti}-(\mathrm{TiAl}) \mathrm{N}-(\mathrm{ZrNbTiAl}) \mathrm{N}$. The tests showed that failures of uncoated ceramic tools follow the exponential distribution law, and the coefficient of failure variation of such tool is 1.08. Meanwhile, the failures of coated ceramic tools follow the law of Weibull distribution, and the coefficients of failure variation are 0.39-0.45, respectively. Thus, it is found out that the deposition of multilayer composite coatings of recommended composition on working surfaces of a tool equipped with cutting inserts of mixed ceramic $\mathrm{Al}_{2} \mathrm{O}_{3}-\mathrm{TiC}$ provides the increased operating reliability of the ceramic tool and predicts its failures.
\end{abstract}

Key words: Cutting ceramic / wear resistance coating / machining of hardened steel / arc-PVD

\section{Introduction}

Growing requirements to cutting tool performance promote further development of the already existing tool materials or development of new ones. At present, the material of cutting ceramic (CC) is successfully applied in the spheres of application, which until recent time predominantly used traditional tool materials (such as carbide). The application of special technologies (mechanical machining, laser machining, ion implantation, and deposition of coating) can significantly improve cutting properties of ceramic [1-3].

The material of mixed ceramic, coated and uncoated, is primary used for machining of hardened steels. The current trend in machine-building industry is to replace grinding with turning in machining of workpieces, such as rotation bodies, of the materials being machined of $\mathrm{H}$ group, with the use of mixed ceramic with coating [4]. At the same time, the above reduces costs and production time.

\footnotetext{
${ }^{a}$ Corresponding author: science@stankin.ru
}

The main feature of $\mathrm{CC}$ is the absence of binding phase, and that fact allows the tool to maintain high strength at heating in wear process and predetermines the possibility to apply high cutting speeds, significantly exceeding the cutting speeds for carbide tools. Another important property of $\mathrm{CC}$ is extremely low tendency to physical and chemical interaction with the materials being machined, and that predetermines the possibility for its efficient use at dry machining without use of $C C$.

However, the material of CC is usually characterized by relatively low toughness and bending strength, high brittleness, and low thermal conductivity with relatively high coefficient of thermal expansion. Thus, cutting tools of $\mathrm{CC}$ are very sensitive to thermal cycling stresses and are characterized by increased tendency to micro- and macrobrittle fracture at contact stresses, exceeding 900$1000 \mathrm{MPa}$. High probability of unpredicted failure (sudden failure) of tools made of CC because of brittle chipping reduces their operational reliability.

One of the most effective methods for complex improvement of physical and chemical properties of a 
ceramic tool to deposit modifying functional coatings on its working surfaces. Resources for complex control over the most important characteristics of cutting process are associated with the phenomenological role of coatings with dual nature, which is reflected in simultaneous improvement of surface properties of ceramic material and reduction of thermomechanical impact on tool contact areas during cutting [5].

Formation of cracks which because of absence of plastic binding phase meet no barriers, able to slow down or stop their development, is the main cause of micro- or macrochipping of tool contact areas already on the stages of running-in or initial phase of steady wear, resulting in tool failure because of brittle fracture. Accumulation and growth of pores promotes the process of coalescence when as a result of interaction, pores began to grow rapidly towards each other, then merge and form cavities-cracks.

The most important criterion of working efficiency of a tool made of cutting ceramic under the conditions of automated blade machining is its reliability, that is, its property to maintain within the period of time the set values of all the parameters, characterizing the tool's ability to perform the required functions within specified limits and conditions of application. Reliability is most often characterized by the average value of tool life and the coefficient of its variation.

The purpose of this paper is to ensure reliability and wear resistance of ceramic cutting tools for processes of continuous cutting of workpieces with increased hardness due application of nanoscale multilayer coatings.

\section{Materials and tools}

The analysis of the methods used to form functional coatings on working surfaces of ceramic blade tool has found out that at present, for the above purposes, the method of Physical Vapour Deposition (PVD) is widely used [6-9]. The concept for formation of modifying coatings for a blade tool made of cutting ceramic was based on the characteristics of physical-mechanical and thermal properties. The fundamental properties of ceramic include:

1. Extremely low thermal conductivity of ceramic in combination with high coefficient of thermal expansion.

2. Low electrical conductivity.

3. High probability of presence of defects in subsurface layers of ceramic cutting inserts, arising during the manufacturing process (sintering, grinding and sharpening).

Therefore, during selection of a method to deposit a coating, the special attention was paid to:

1. Possibility of maximum positively directed "healing" effect on surface defects of ceramic (microcracks, micropores, residual strain stresses, etc.), in order to minimize or eliminate them.
2. Maximum reduction in the level of negative residual strain stresses (formed after sharpening of working surfaces of ceramic tool) or their transformation into more acceptable residual strain stresses to reduce the likelihood of sudden (unpredicted) failure of ceramic tool as a result of formation and development of microcracks, resulting in brittle fracture of its cutting part.

To produce modifying effect on working surfaces of ceramic tool, the study involved the innovative process, named as "filtered vacuum arc deposition" and implemented at unit VIT-2 [10-13]. The use of the above method does not result in structural changes in ceramic material and ensures the following:

- high adhesive strength of coating with regard to ceramic substrate;

- control over the level of "healing" energy effect on surface defects of ceramic in the form of microcracks and micropores, as well as formation of favourable residual strain stresses in surface layers of the ceramic material;

- formation of nanoscale structure of deposited layers of coating (grain size, thickness of sublayers).

As an object of the tests, the study involved a cutting tool of ceramic of "mixed" type $\left(\mathrm{Al}_{2} \mathrm{O}_{3}-\mathrm{TiC}\right)$, considerably wide used in modern production.

Cutting properties of ceramic tools were studied at longitudinal turning of workpieces of hardened steel $\mathrm{X} 153 \mathrm{CrMoV} 12$ under the following cutting conditions: $v_{c}=500 \mathrm{~m} / \mathrm{min} ; a_{p}=0.1 \mathrm{~mm} ; f=0.1 \mathrm{~mm} / \mathrm{rev}$.

For microstructural tests of samples, a scanning electron microscope (SEM) FEI Quanta 600 FEG was used.

\section{Discussion of results}

\subsection{Study of wear mechanism of ceramic cutting inserts}

The study included testing of wear mechanism of ceramic inserts without coating and with nanoscale multilayer composite coating (NMCC) Ti-TiAlN(ZrNbTiAl)N. It is found out that the failure of uncoated cutting inserts occurs as a result of "brittle fracture", with formation of numerous cracks (Fig. 1). Meanwhile, the tests discovered diffusion of $\mathrm{Fe}$ from the material being machined into internal surfaces of the formed cracks, in fact, virtually along their entire length.

The nature of development of wear centres on rake and flank faces of cutting inserts of ceramic $\mathrm{Al}_{2} \mathrm{O}_{3}-\mathrm{TiC}$ with coatings Ti-TiAlN-(ZrNbTiAl)N and Ti-(TiAl)N$(\mathrm{TiCrAl}) \mathrm{N}$ at longitudinal turning of hardened steel X153CrMoV12 under the above conditions of machining is of balance nature without visible chips and microchipping. The tests have also discovered undisturbed residues of coatings on the edges of both rake and flank surfaces of the ceramic cutting inserts (Fig. 2). 

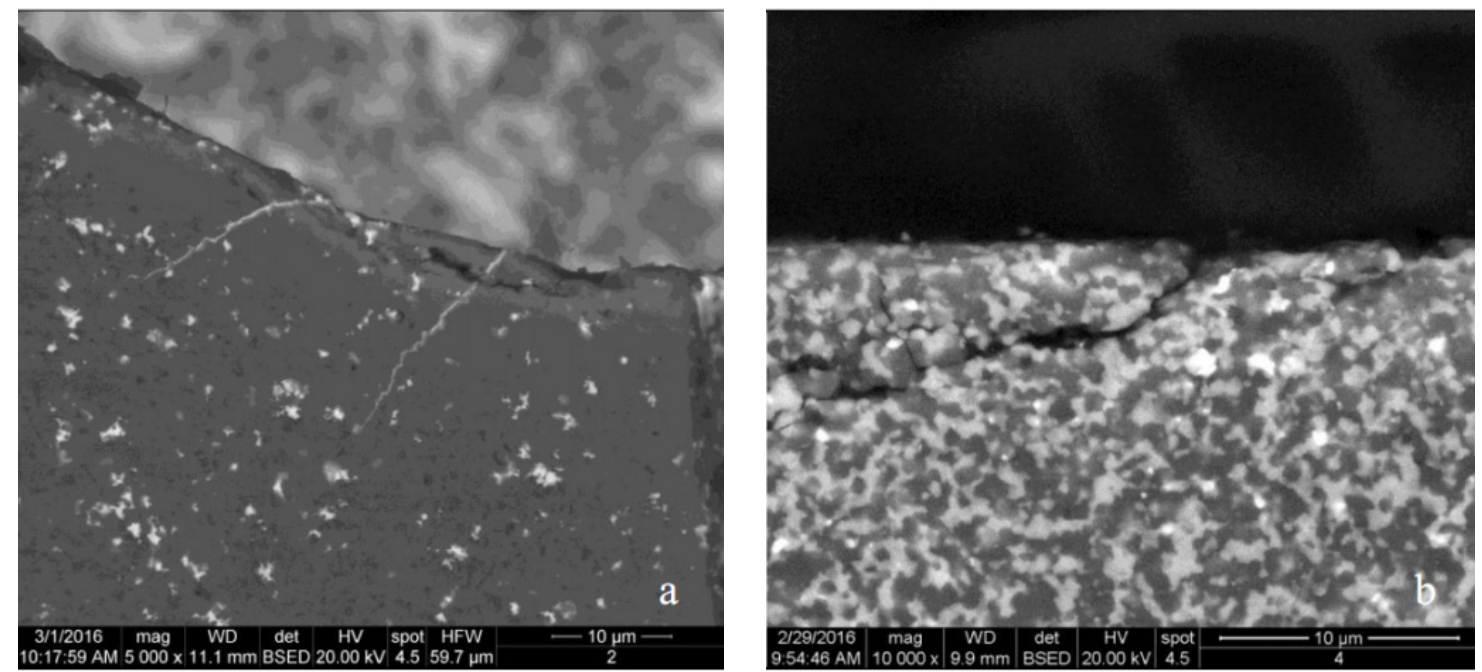

Fig. 1. Brittle fracture and structure of a crack in substrate $\mathrm{Al}_{2} \mathrm{O}_{3}-\mathrm{TiC}$ without coating after 10 min of longitudinal turning of workpieces of hardened steel X153CrMoV12 under the following conditions of machining: $v_{c}=500 \mathrm{~m} / \mathrm{min} ; a_{p}=0.1 \mathrm{~mm}$; $f=0.1 \mathrm{~mm} / \mathrm{rev}$.
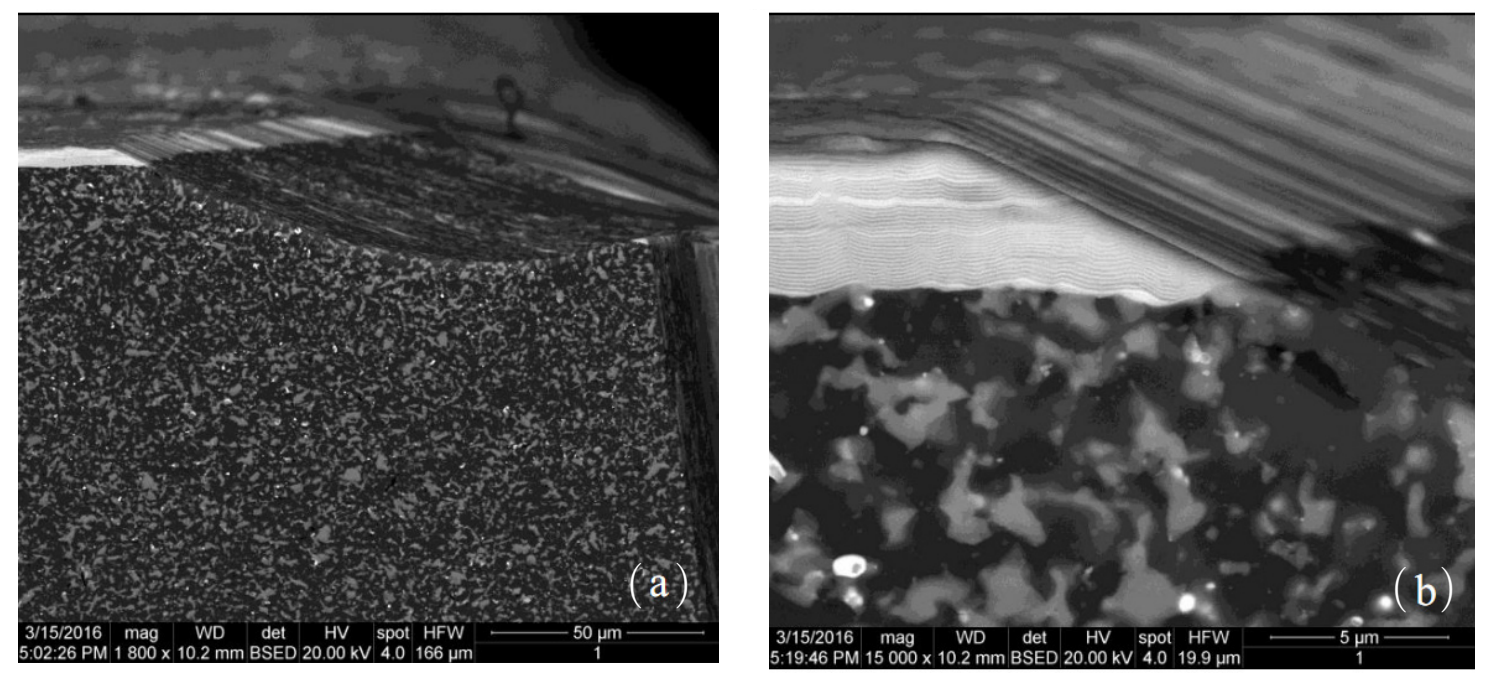

Fig. 2. Wear of rake face of ceramic insert $\mathrm{Al}_{2} \mathrm{O}_{3}-\mathrm{TiCwith}$ coating Ti-TiAlN-(ZrNbTiAl)N after 10 min of longitudinal turning of workpieces of hardened steel X153CrMoV12. Find conditions of machining in Figure 1.

The analysis of the results of the study of kinetics of wear of contact areas on rake and flank faces of the tool allows noting the following.

To study the kinetics of formation of tool wear spots, tests were carried out in longitudinal turning and the results are presented in Figures 3 and 4. The comparison of the kinetics of tool wear in mixed ceramic $\mathrm{Al}_{2} \mathrm{O}_{3}$ TiC with Ti-( TiAl)N-( TiCrAl)N coating and control uncoated CI in turning with $v_{c}=500 \mathrm{~m} / \mathrm{min} ; a_{p}=0.1 \mathrm{~mm}$; $f=0.1 \mathrm{~mm} / \mathrm{rev}$ showed that the wear rate for uncoated cutting instrument (CI) is significantly higher than the wear rate for the tools with NMCC (see Figs. 3 and 4). The centre of rake surface of CI is localized in the area of the edges on rake surface with negative rake angle (see Fig. 4), and it does not have any decisive influence on the performance of the tool. In most cases, flank wear land was assumed as a criterion of tool failure.

The difference between flank wear land $V B$ for uncoated ceramic tool and the coated with NMCC reached 20-30 $\mu \mathrm{m}$ for a cutting time of $10 \mathrm{~min}$.

\section{Reliability of ceramic cutting tool with elaborated coatings}

The cutting inserts of SNUN shape (ISO) made of mixed ceramic $\mathrm{Al}_{2} \mathrm{O}_{3}-\mathrm{TiC}$ with $\mathrm{Zr}-\mathrm{ZrN}-(\mathrm{Ti}, \mathrm{Zr}) \mathrm{N}$ and Ti$(\mathrm{TiAl}) \mathrm{N}-(\mathrm{TiCrAl}) \mathrm{N}$ coating were studied. The tests were conducted with the following cutting parameters: $v_{c}=$ $500 \mathrm{~m} / \mathrm{min}, f=0.1 \mathrm{~mm} / \mathrm{rev} ; a_{p}=0.1 \mathrm{~mm}$, while toughness of the machined surface was about $R_{a}=0.8-0.6 \mu \mathrm{m}$. 
S.N. Grigoriev and A.A. Krapostin: Mechanics \& Industry 17, 704 (2016)

\section{$\mathrm{Al}_{2} \mathrm{O}_{3}$-TiC insert with Ti-(TiAl)N- (TiCrAl)N}

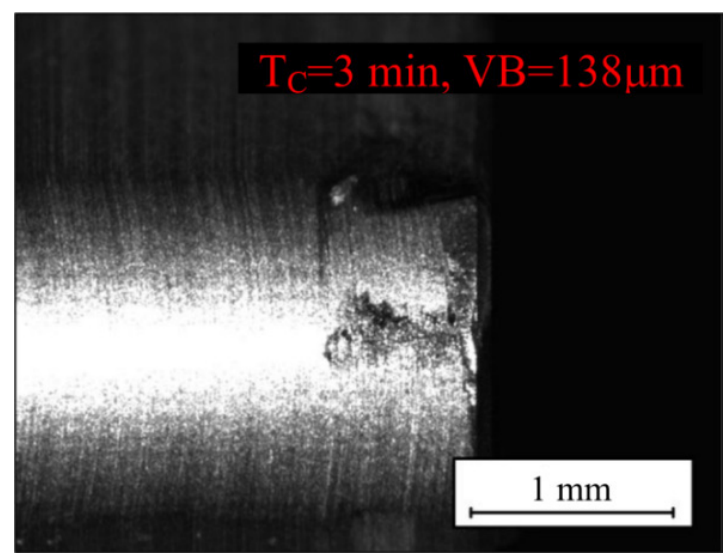

(a)

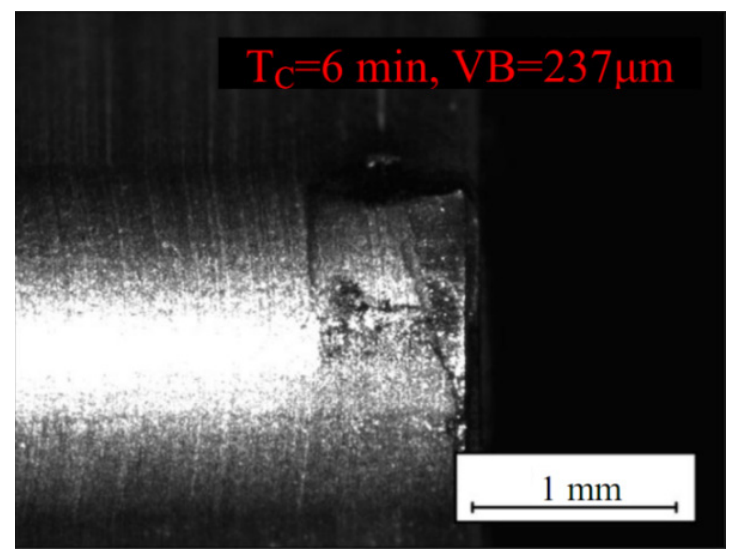

(c)

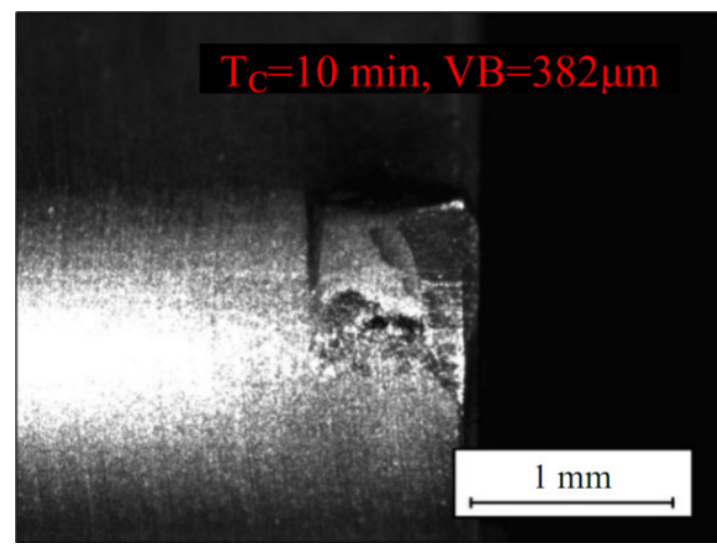

(e)
Uncoated cutting insert $\mathrm{Al}_{2} \mathrm{O}_{3}-\mathrm{TiC}$

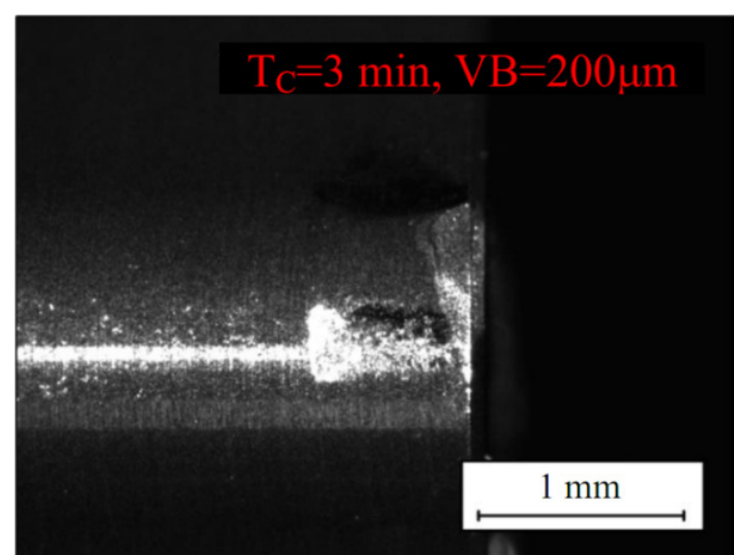

(b)

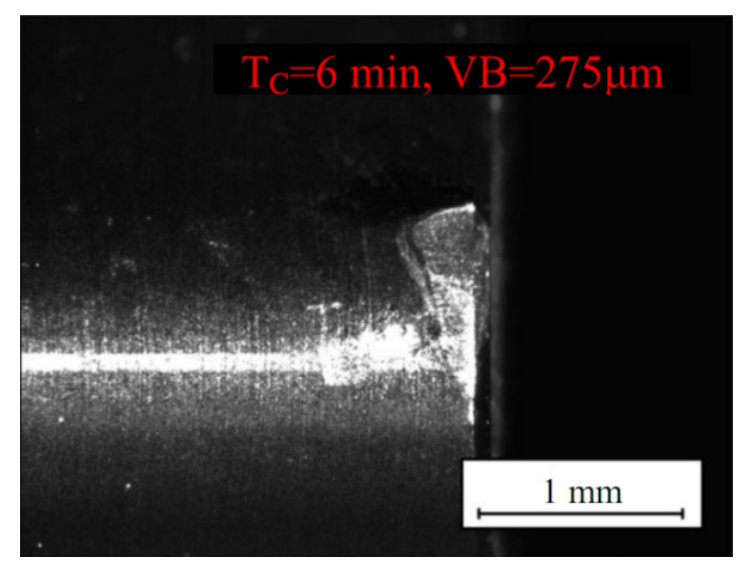

(d)

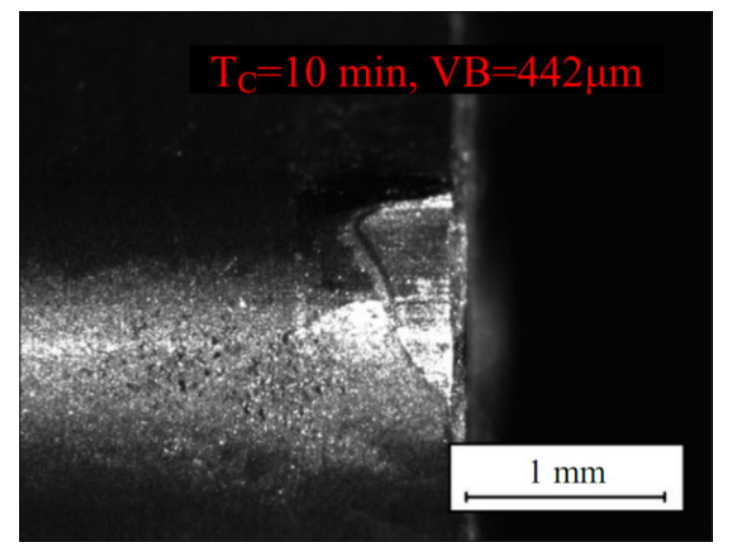

(f)

Fig. 3. Kinetics of flank wear land $V B$ of CI with mixed ceramic $\mathrm{Al}_{2} \mathrm{O}_{3}-\mathrm{TiC}$ with NMCC Ti-(TiAl)N-(TiCrAl)N (a,c,e) and uncoated mixed ceramic $\mathrm{Al}_{2} \mathrm{O}_{3}-\mathrm{TiC}(\mathrm{b}, \mathrm{d}, \mathrm{f})$ in longitudinal turning of hardened steel X153CrMoV12. 
S.N. Grigoriev and A.A. Krapostin: Mechanics \& Industry 17, 704 (2016)

$\mathrm{Al}_{2} \mathrm{O}_{3}$-TiC insert with Ti-(TiAl)N$(\mathrm{TiCrAl}) \mathrm{N}$

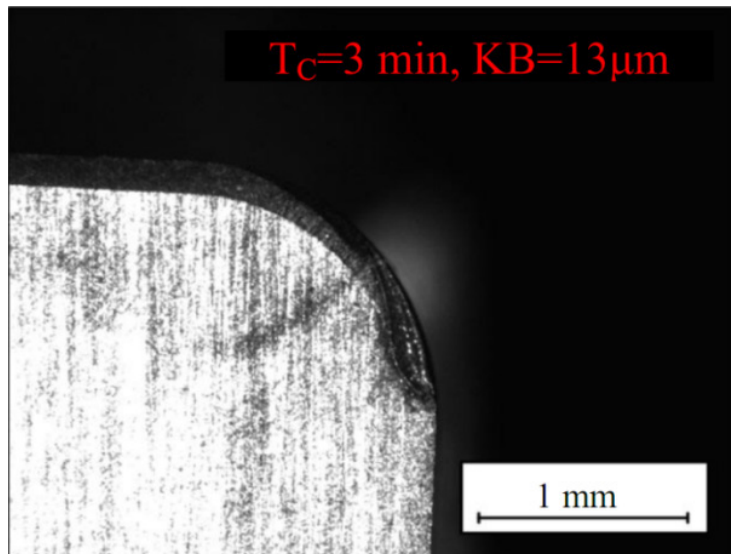

(a)

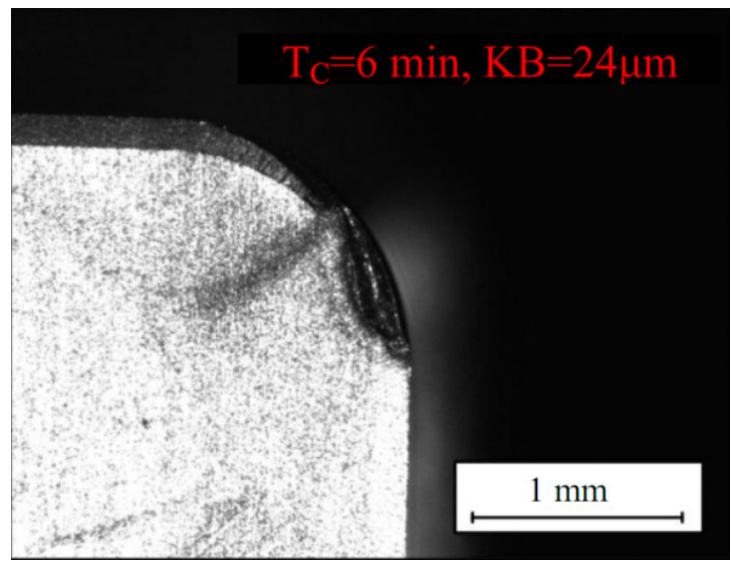

(c)

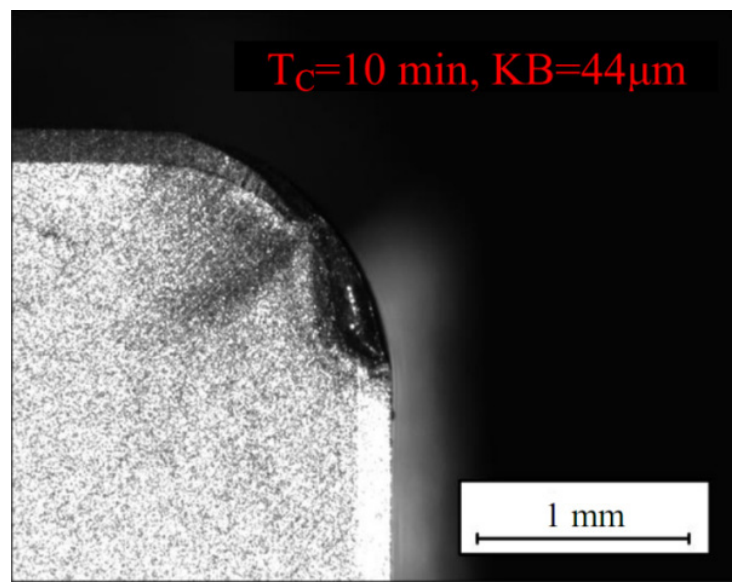

(e)
Uncoated cutting insert Al2O3-TiC

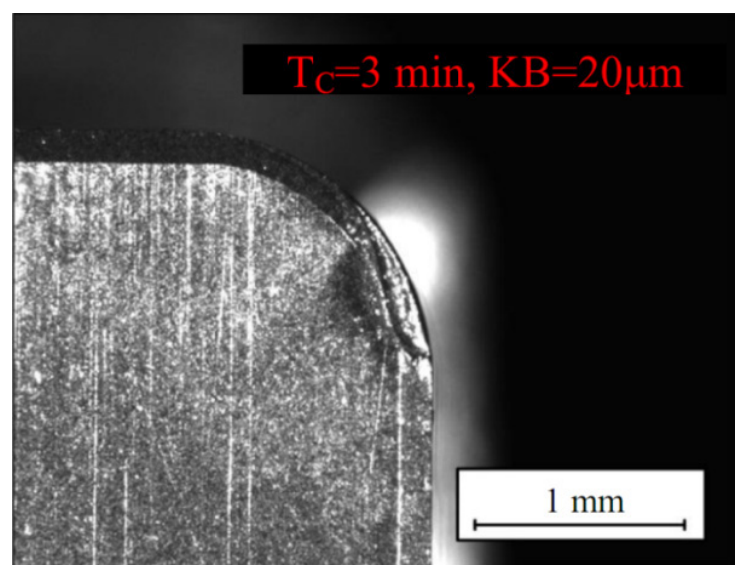

(b)

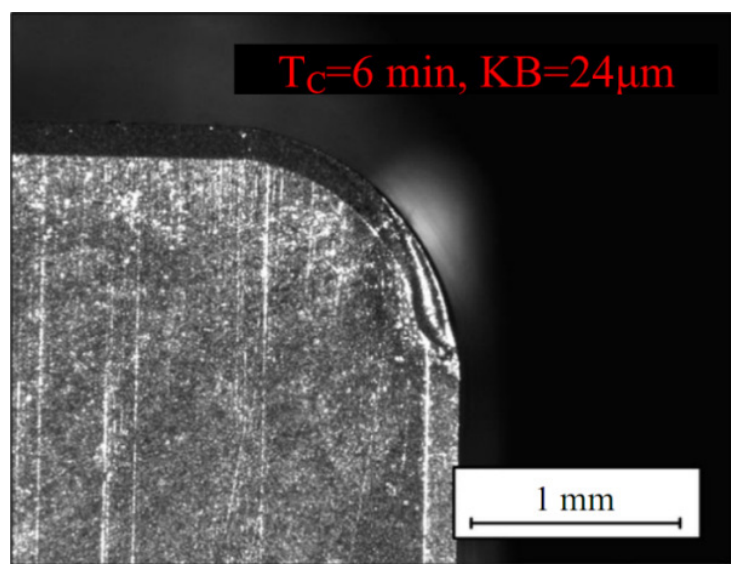

(d)

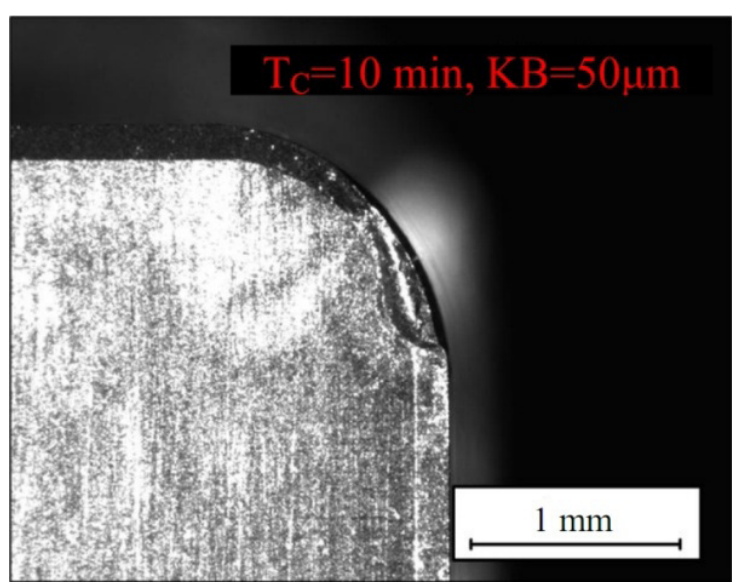

(f)

Fig. 4. Kinetics of rake wear land $K B$ of $\mathrm{CI}$ with mixed ceramic $\mathrm{Al}_{2} \mathrm{O}_{3}-\mathrm{TiC}$ with $\mathrm{NMCC} \mathrm{Ti}-(\mathrm{TiAl}) \mathrm{N}-(\mathrm{TiCrAl}) \mathrm{N}$ (a,c,e) and uncoated $(\mathrm{b}, \mathrm{d}, \mathrm{f})$, in turning hardened steel X153CrMoV12 at $v_{c}=500 \mathrm{~m} / \mathrm{min} ; a_{p}=0.1 \mathrm{~mm} ; f=0.1 \mathrm{~mm} / \mathrm{rev}$. 
The study determined the scale of an ordered series of intervals, hit rate $r_{j}$ of a random variable in specific interval, hit rate $p_{j}$ of a random variable in specific interval, and accumulated frequency of occurrence $S\left(p_{j}\right)$.

$$
p_{j}=r_{j} / \delta
$$

where $r_{j}$ - hit rate of a random variable in specific interval, and $\delta$ is wear intensity (relative tool wear) - a derivative of the wear on the cutting way $L$ at any given moment.

$$
\begin{aligned}
\delta & =\frac{\mathrm{dVB}}{\mathrm{d} L} \\
t_{\text {jmed }} & =\left(t_{j}+t_{j+1}\right) / 2 .
\end{aligned}
$$

The mean time between failure (MTBF) and the coefficient of variation were defined as:

$$
\begin{aligned}
T_{o} & =\left(\sum t_{\text {jmed }} \cdot r_{j}\right) / \sum r_{j}, \\
V(X) & =\sigma(x) / T,
\end{aligned}
$$

The use of an exponential distribution law allowed defining the basic parameters of reliability:

Failure rate

$$
\xi=1 / T_{o},
$$

Probability of failure-free operation

$$
P(t)=e^{-\xi t} .
$$

Probability of failure

$$
Q(t)=1-P(t)
$$

Failure flow parameter

$$
a(t)=f(t)=\xi e^{-\xi t} .
$$

Figure 5 presents the results of tests in the form of dependence of probability of tool failures from flank wear land $V B$.

Observation of failures of tool with mixed ceramic $\mathrm{Al}_{2} \mathrm{O}_{3}$-TiC depending on the type of coating, showed that ceramic $\mathrm{Al}_{2} \mathrm{O}_{3}$-TiC-based tool with NMCC has lower probability of failure. Failure of NMCC, indicators of reliability of ceramic tool significantly reduce when flank wear land $V B$ is greater than $0.3 \mathrm{~mm}$. The deposition of NMCC on ceramic tool reduces the probability of failure by $4-5 \%$ with reference to uncoated tool.

The operational reliability of the tool with mixed ceramic was determined by assessing the following parameters using statistical processing [14-18]:

- scope of variation;

- range of specific interval;

- scale of intervals of ordered series; frequency of random variable falling in specific range;

- frequency of random variable $r_{j}$ in specific interval;

- calculated frequency of random variable $p_{j}$ falling in specific range;
- calculated frequency accumulation $S\left(p_{j}\right)$. The data obtained were used to determine the average time between failures, mean square deviation and coefficient of variation.

It was found that the coefficient of failure variation for $\mathrm{Al}_{2} \mathrm{O}_{3}$-TiC-based CI with Ti- $(\mathrm{TiAl}) \mathrm{N}-(\mathrm{TiCrAl}) \mathrm{N}$ was $0.39-0.41$, and the coefficient of failure variation for $\mathrm{Al}_{2} \mathrm{O}_{3}$-TiC-based CI with Ti-TiAlN-(ZrNbTiAl)N was $0.44-0.45$.

Using reliability theory it is postulated that: If the coefficient of tool failure variation does not exceed 0.5 , the variation range of tool failure values, resulting from the experiment, will obey the law of Weibull distribution $[19,20]$. In the specified type of distribution, it can be noted that the wear process for cutting tool, the wear moves from the stage of a sudden failure at any moment of time to the stage of forecasted (predictable) failure.

In the two-parameter Weibull distribution, $\lambda_{0 w}$ determines the scale and $\alpha_{W}$ is the asymmetry for sufficient accuracy of prediction of the reliability of the tested ceramic cutting tool with the parameter of time between failures.

The parameter $\alpha_{W}$ can be used for easy identification of analytical description for different experimental dependences. For $\alpha_{W}=1$, Weibull distribution is transformed into an exponential distribution. When $\alpha_{W}<1$, failure rate decreases monotonically over time, and when $\alpha_{W}>1$, it increases monotonically. While selecting $\alpha_{W}$, it is possible to achieve approximation of analytical distribution function to the experimental data.

The dependences (Figs. 6-9) are obtained by calculations of the basic reliability parameters of Weibull distribution.

The data presented in Figures 6-9 show that, the increase in the parameters of the reliability of ceramic tool with NMCC compared to the corresponding parameters of uncoated ceramic tool suggests that the deposition of NMCC enhances the reliability of ceramic tool. In particular, the studies of tool with mixed ceramic with NMCC have shown that failures of ceramic tool with NMCC obey the law of Weibull distribution, and the coefficients of failure variation are $0.39-0.45$, respectively.

It was found that failure of the tools with mixed ceramic $\left(\mathrm{Al}_{2} \mathrm{O}_{3}\right.$-TiC), are a subject to exponential distribution, and the coefficient of tool failure variation is 1.08. The deposition of $\mathrm{Ti}-(\mathrm{TiAl}) \mathrm{N}-(\mathrm{TiCrAl}) \mathrm{N}$ and $\mathrm{Ti}-$ (TiAl)N-(ZrNbTiAl)N coatings on mixed ceramic decreases the coefficient of tool failures down to 0.41 and 0.44 , respectively, leading to the distribution of tool failures to follow Weibull distribution.

\section{Conclusions}

Based on the conceptual provision on dual nature of coating as process medium between the material being machined and the ceramic substrate, the paper has developed and studied nanoscale multilayered composite coatings for ceramic tools. The outer wear-resistant 


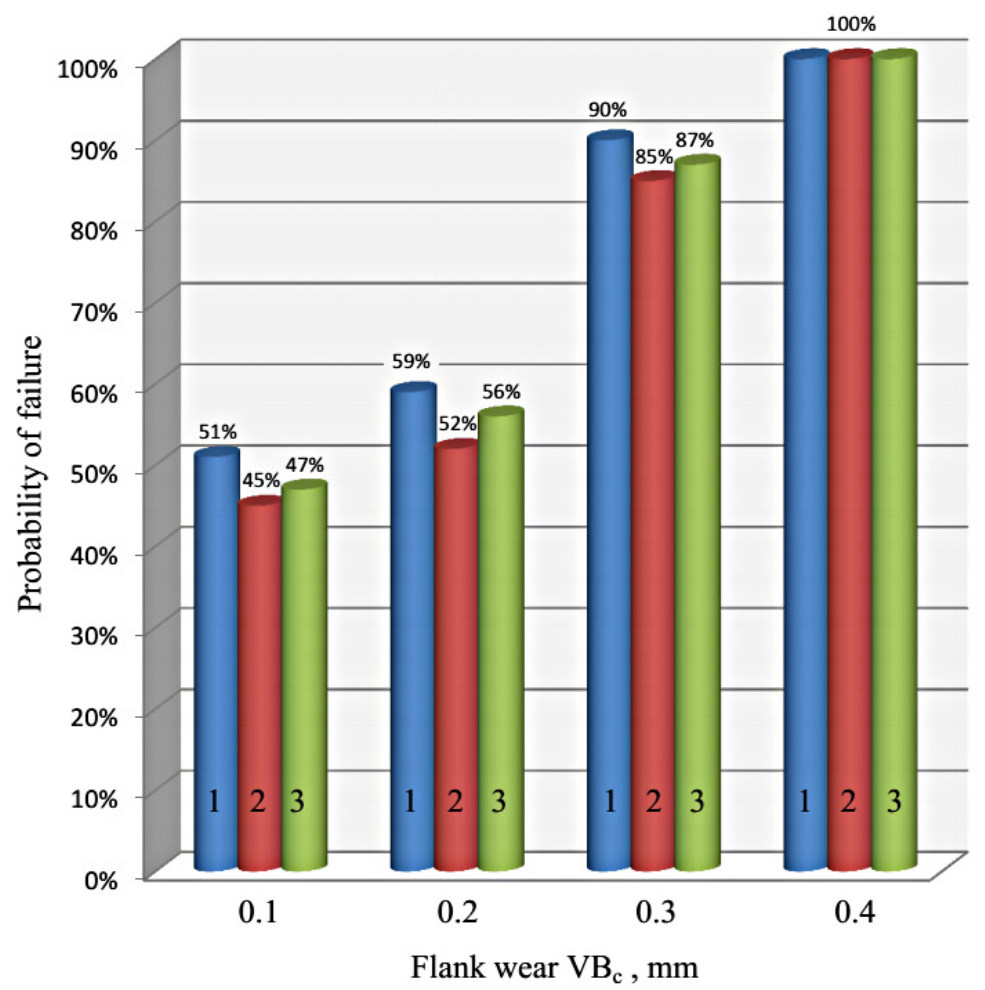

Fig. 5. Failure probability as function of flank wear land $V B$ in turning X153CrMoV12 $(\mathrm{HRC} 60)$ at $v_{c}=500 \mathrm{~m} / \mathrm{min}$; $f=0.1 \mathrm{~mm} / \mathrm{rev} ; a_{p}=0.1 \mathrm{~mm}$ with $\mathrm{Al}_{2} \mathrm{O}_{3}-\mathrm{TiC}$ insert: 1 - uncoated, 2 - Ti-(TiAl)N-(TiCrAl)N, $3-\mathrm{Ti}-(\mathrm{TiAl}) \mathrm{N}-(\mathrm{ZrNbTiAl}) \mathrm{N}$.

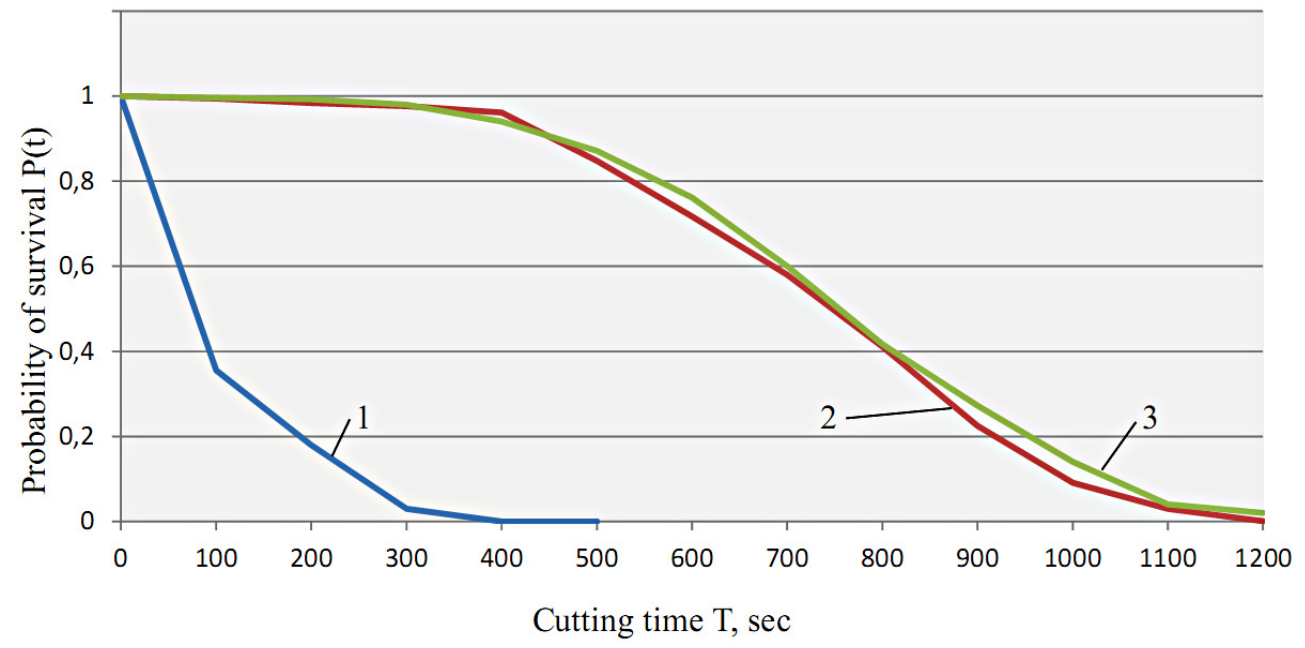

Fig. 6. Probability of failure-free as function of operating time. 1 - Uncoated, 2 - Ti-(TiAl)N-(TiCrAl)N, $3-\mathrm{Ti}-(\mathrm{TiAl}) \mathrm{N}-$ (ZrNbTiAl)N.

layer of such coatings, which contacts the material being machined, is designed to reduce normal and tangential (shear) stresses and to increase brittle strength of tool cutting edge. The adhesive layer, which contacts ceramic substrate, provides high strength of adhesion of the coating to the ceramic substrate, while the intermediate layer increases the strength of adhesion between adhesive and wear-resistant layer of coating.

It is found out that coatings reduce the wear rate of a ceramic tool along its flank face. The difference between flank wear land $V B$ for an uncoated ceramic tool and a ceramic tool with coating reaches up to $60 \mu \mathrm{m}$ during cutting time of 10-12 min, with the better results on reduction of the wear rate of flank wear land shown by ceramic cutting inserts with nanoscale multilayer coating Ti-(TiAl)N-(TiCrAl)N as compared with coating Ti(TiAl)N-(ZrNbTiAl)N.

The study has experimentally found out the dependence of failure rate of a tool of cutting ceramic from flank wear land. It is shown that flank wear land $V B>0.2 \mathrm{~mm}$ 
S.N. Grigoriev and A.A. Krapostin: Mechanics \& Industry 17, 704 (2016)

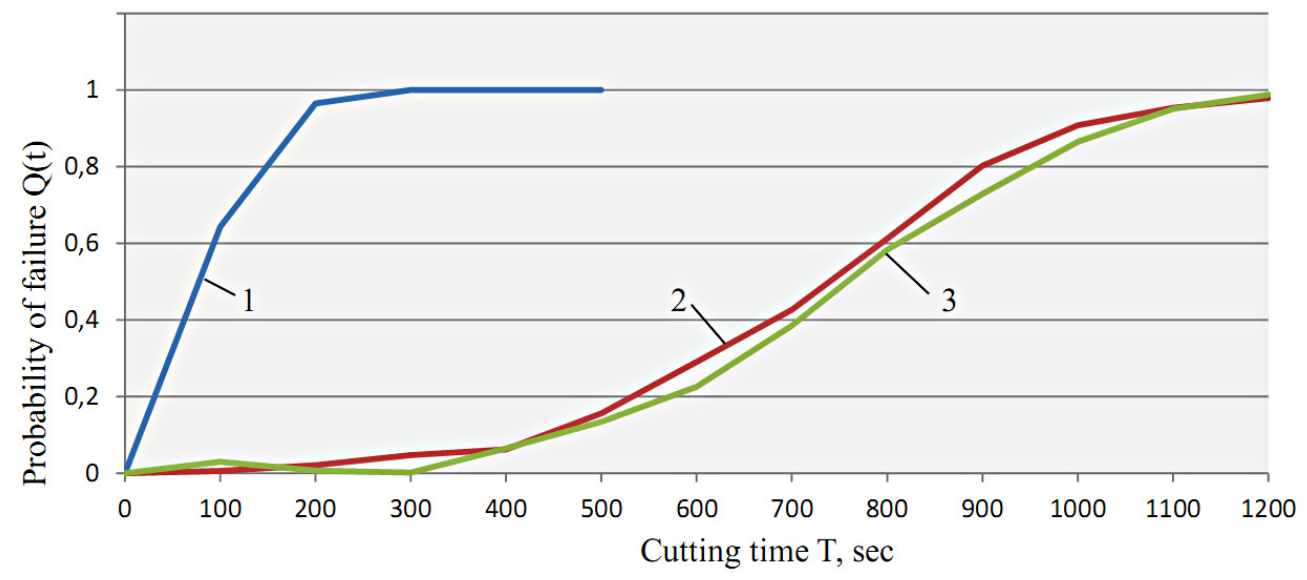

Fig. 7. Probability of failure as function of operating time. 1 - Uncoated, 2 - Ti-(TiAl)N-(TiCrAl)N, $3-\mathrm{Ti}-(\mathrm{TiAl}) \mathrm{N}-$ (ZrNbTiAl)N.

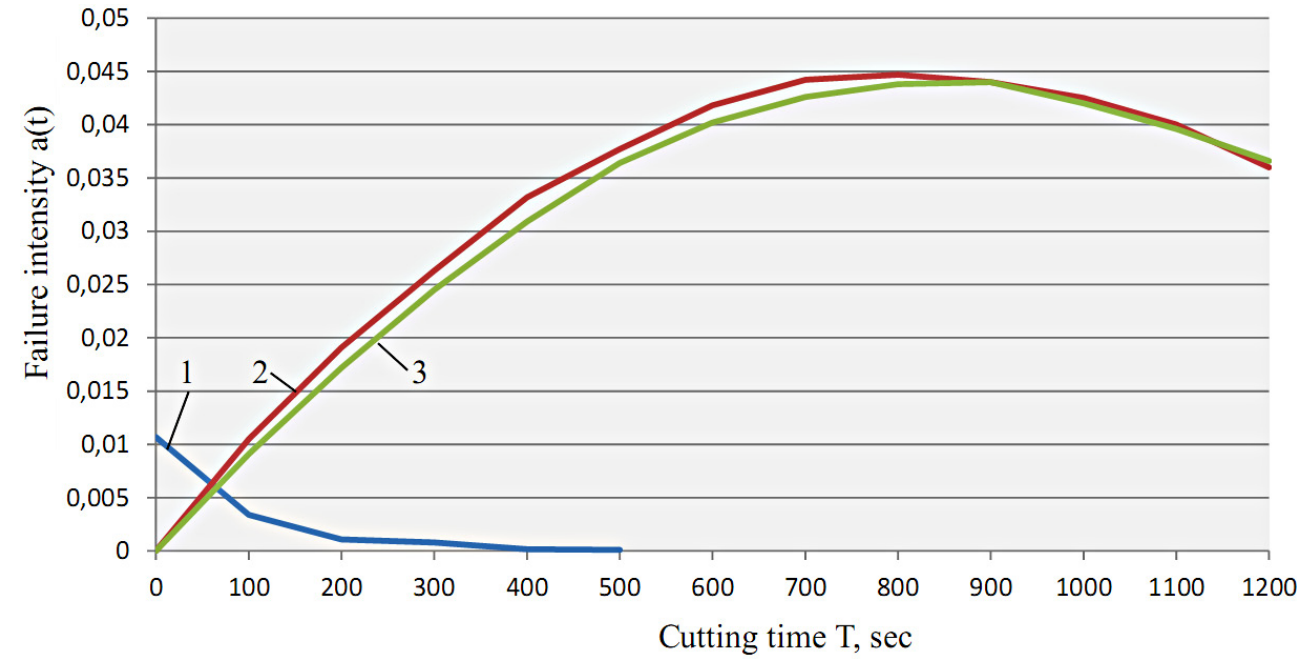

Fig. 8. Dependence of the distribution flow on time. 1 - Uncoated, $2-\mathrm{Ti}-(\mathrm{TiAl}) \mathrm{N}-(\mathrm{TiCrAl}) \mathrm{N}, 3-\mathrm{Ti}-(\mathrm{TiAl}) \mathrm{N}-(\mathrm{ZrNbTiAl}) \mathrm{N}$.

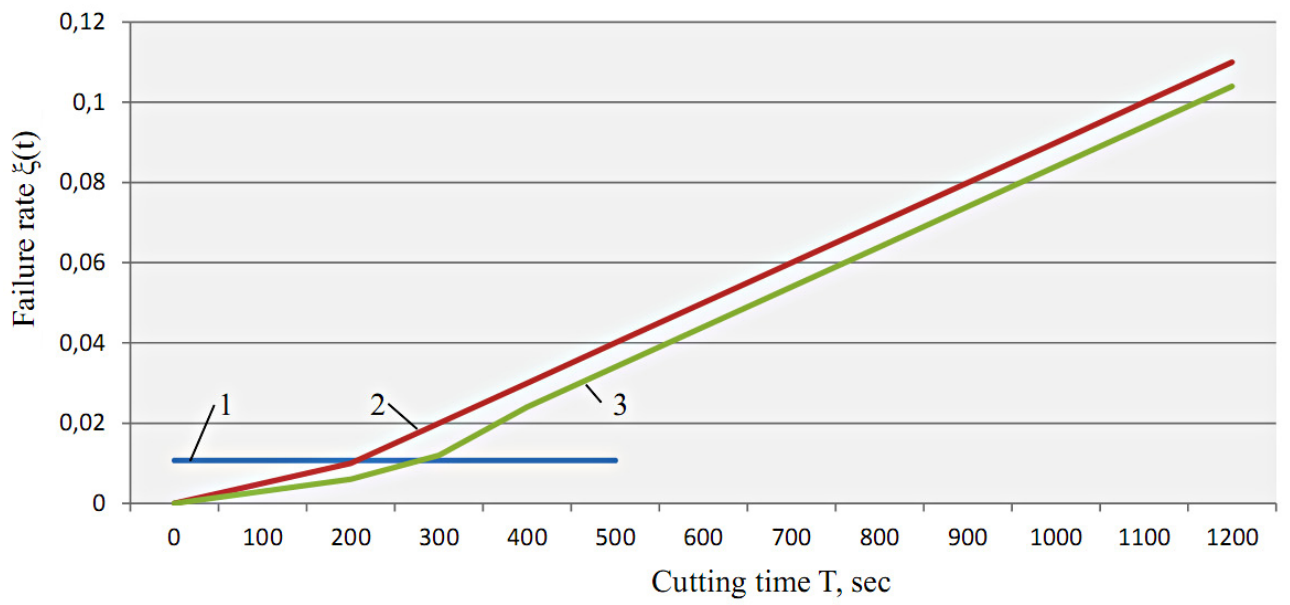

Fig. 9. Dependence of the failure rate on time. 1 - Uncoated, $2-\mathrm{Ti}-(\mathrm{TiAl}) \mathrm{N}-(\mathrm{TiCrAl}) \mathrm{N}, 3-\mathrm{Ti}-(\mathrm{TiAl}) \mathrm{N}-(\mathrm{ZrNbTiAl}) \mathrm{N}$. 
of a blade cutting tool of ceramic $\mathrm{Al}_{2} \mathrm{O}_{3}$-TiC increases the likelihood of chipping of cutting wedge and thus has a negative effect on failure variation and reliability of ceramic tool.

The study has found out the laws of distribution of tool life of tools made of mixed cutting ceramic with coatings and without coatings at machining of hardened steels with hardness of $\mathrm{HRC}>52$. It is shown that the tool life variations (coefficients of failure variation) of a tool equipped with cutting inserts of ceramic $\mathrm{Al}_{2} \mathrm{O}_{3^{-}}$ $\mathrm{TiC}$ without coating follow the exponential distribution law, and the coefficient of failure variation is 1.08. Failure variations for cutting inserts of $\mathrm{Al}_{2} \mathrm{O}_{3}-\mathrm{TiC}$ with developed coatings Ti-(TiAl)N-(TiCrAl)N and Ti-(TiAl)N(ZrNbTiAl)N, obtained through the technology of filtered vacuum arc deposition, were 0.38 and 0.44 , respectively, and followed the law of Weibull distribution.

Thus, it is found out that the deposition of multilayer composite coatings of recommended composition on working surfaces of a tool equipped with cutting inserts of mixed ceramic $\mathrm{Al}_{2} \mathrm{O}_{3}$-TiC provides the increased operating reliability of a ceramic tool and predicts its failures.

Acknowledgements. The work is performed with financial support of the Russian Science Foundation within the Agreement No.14-29-00297 of August 6, 2014.

\section{References}

[1] R. Riedel Handbook of Ceramic Hard Materials, Weinheim, NewYork: WILEY-VICH, 2000

[2] L.N. López de Lacalle, A. Lamikiz, Machine Tools for High Performance Machining, Springer, 2009

[3] E.S. Sotova, A.A. Vereshchaka, A.S. Vereshchaka, Ceramic cutting tools, Publishing MSTU "STANKIN", Moscow, 2013

[4] E. Brinksmeier, S. Bartsch, Ceramic Tools - Material and Load Types Determine Wear Mechanisms, Annals of the CIRP 37-1 (1988) 97-100

[5] S.N. Grigoriev, A.A. Vereschaka, A.S. Vereschaka, A.A. Kutin, Cutting tools made of layered composite ceramics with nano-scale multilayered coatings, Procedia CIRP 1 (2012) $318-323$

[6] A.S. Vereschaka, S.N. Grigoriev, E.S. Sotova, A.A. Vereschaka, Improving the efficiency of the cutting tools made of mixed ceramics by applying modifying nanoscale multilayered coatings, Adv. Mater. Res. 712-715 (2013) 391-394

[7] A.S. Vereschaka, S.N. Grigoriev, V.P. Tabakov, E.S. Sotova, A.A. Vereschaka, M.Yu. Kulikov, Improving the efficiency of the cutting tool made of ceramic when machining hardened steel by applying nano-dispersed multilayered coatings, Key Eng. Mater. 581 (2014) 68-73
[8] A.A. Vereshchaka, E.S. Sotova, A.D. Batako, M.I. Sedykh, A.S. Vereshchaka, A Study of the Cutting Properties and Wear Mechanism of Ceramic Edge Tools with Nanostructure Multilayer Composite Coatings, J. Friction Wear 35-6 (2014) 483-488

[9] A.A. Vereshchaka, A.D. Batako, E.S. Sotova, A.S. Vereshchaka, Nanostructured multilayer composite coatings on ceramic cutting tools for finishing treatment of high-hardness quenched steels, Metal Sci. Heat Treatment 57 (2016) 614-621

[10] A.A. Vereschaka, J. Prilukova, B.Y. Mokritskii, A.S. Vereschaka, N. Sitnikov, Specifics of application of cutting ceramics with functional coating in turning of highstrength materials, Mater. Sci. Forum 857 (2016) 221-227

[11] K. Czechowski, et al., Effect of nitride nano-scale multilayer coatings on functional properties of composite ceramic cutting inserts, Bulletin of the Polish Academy of Sciences. Technical Sciences 53 (2005) 425-431

[12] M. Sokovic, J. Kopac, L.A. Dobrzanski, J. Mikula, K. Golombek, D. Pakula, Cutting Characteristics of PVD and CVD - Coated Ceramic Tool Inserts, Tribology in Industry 28 (2006) 3-8

[13] L.A. Dobranski, D. Pakula, A. Kriz, M. Sokovic, J. Kopac, Tribological Propertes of the PVD and CVD Coatings Deposition on Nitride Tool Ceramic, J. Mater. Process. Technol. 175 (2006) 179-185

[14] L.A. Dobranski, J. Mikula, The Structure and Properties of PVD and CVD Coated $\mathrm{Al}_{2} \mathrm{O}_{3}$-TiC Mixed Oxide Tool Ceramic for Dry on High Speed Cutting Processes, J. Mater. Process. Technol. 64-165 (2005) 822-831

[15] A.A. Vereshchaka, A.S. Vereshchaka, O. Mgaloblishvili, M.N. Morgan, A.D. Batako, Nanoscale multilayered-composite coatings for the cutting tools, Int. J. Adv. Manuf. Technol. 72-1 (2014) 303-317

[16] A.O. Volkhonskii, A.A. Vereshchaka, I.V. Blinkov, A.S. Vereshchaka, A.D. Batako, Filtered cathodic vacuum Arc deposition of nano-layered composite coatings for machining hard-to-cut materials, Int. J. Adv. Manuf. Technol. 84 (2016) 1647-1660

[17] A.S. Vereschaka, A.A. Vereschaka, D.V. Sladkov, A. Yu. Aksenenko, N.N. Sitnikov, Control of structure and properties of nanostructured multilayer composite coatings applied to cutting tools as a way to improve efficiency of technological cutting operation, J. Nano Res. 37 (2016) $51-57$

[18] A.S. Vereshchaka, V.S. Kushner, Rezaniye materialov, Vysshaya Shkola, Moskva, 2009

[19] G. Brandt, Thermal Shock Resistance of Ceramic Cutting Tools, Surf. Eng. 2 (1986) 121-131

[20] M. Bengisu, Engineering Ceramics, Springer-Verlag, Berlin Heidelberg, 2001 